\title{
IMPACTOS DA UTILIZAÇÃO DA TRILHA PARA A PISCINA DO CAIXA D'AÇO NO PARQUE NACIONAL DA SERRA DA BOCAINA, PARATY (RJ)
}

\author{
Luana de Almeida Rangel ${ }^{1}$ \\ Marcelo Aurélio Pereira da Silva ${ }^{2}$ \\ Antonio José Teixeira Guerra ${ }^{3}$
}

\section{RESUMO}

As Unidades de Conservação (UCs) são áreas naturais delimitadas e protegidas por lei, visando à preservação dos recursos naturais e da biodiversidade. Como, normalmente, os atrativos naturais das UCs estão localizados em áreas de difícil acesso, se faz necessária abertura de trilhas. Quando não ocorre planejamento para sua implementação e o uso é intensivo, diversos impactos negativos no solo e no ecossistema podem ser observados, como a compactação, diminuição da porosidade e da percolação de água. Nesse contexto, esta pesquisa tem como objetivo analisar o impacto da utilização da trilha que leva à Piscina Natural do Caixa D'Aço localizada no Parque Nacional da Serra da Bocaina (PNSB), no município de Paraty (RJ). O PNSB foi escolhido como área de estudo por ser uma das maiores UCs no bioma Mata Atlântica e por estar sofrendo pressão direta da expansão urbana e do aumento da atividade turística. Para isso, foram coletadas amostras de solo em três pontos da trilha nas profundidades de $0-10 \mathrm{~cm}$. Foram analisadas a textura - método de dispersão de partículas; a densidade do solo e de partículas; e a porosidade. Para cada análise foram feitas três repetições, a fim de realizar teste estatístico. A partir da pesquisa descritiva de observação dos impactos e das análises físicas do solo, concluiu-se que o aumento da visitação turística, quando não é bem planejado e/ou gerido, está impactando negativamente nas condições da trilha e há necessidade de implementação de novas estruturas de manejo.

Palavras-Chave: Áreas Protegidas, Trilhas, Propriedades Físicas do Solo

\begin{abstract}
Conservation Units are natural areas protected and delimited by laws that aim to preserve natural resources and biodiversity. Considering that the natural attractions of the Conservation Units are usually located in difficult access areas, man-made trails are often a necessity. When no implementation plan is made for trails and there is intensive use, several negative impacts can be observed, such as soil compaction, reduced porosity and water percolation. In this context, this research aims to analyze the impacts of the use of the trail that leads to Natural Swimming of "Caixa D'Aço", located in Serra da Bocaina National Park (PNSB), in Paraty Municipality (Rio de Janeiro State). The PNSB was chosen as the study area because it is one of the largest protected areas in the Atlantic Forest and is suffering directly from urban sprawl and increasing tourism. For this purpose, soil samples were collected from three trail spots with depths ranging from 0 to $10 \mathrm{~cm}$. We analyzed the texture (through the particles scattering method); soil and paticle density; and porosity. Each test was performed three times, in order to perform statistical tests. Through descriptive research of the impacts and through physical analysis of the soil, a conclusion was reached that the increase in tourist visits, when not well planned and/or well managed, impacts negatively on the trail condition and that implementation of new management plans are necessary.
\end{abstract}

Keywords: Protected Areas, Trails, Soil physical properties

\footnotetext{
${ }^{1}$ Doutoranda em Geografia pela Universidade Federal do Rio de Janeiro, Integrante do LAGESOLOS - E-mail: luarangel@ufrj.br

${ }^{2}$ Graduando em Geografia pela Universidade Federal do Rio de Janeiro, Integrante do LAGESOLOS

${ }^{3}$ Professor Titular do Departamento de Geografia da Universidade Federal do Rio de Janeiro - Coordenador do LAGESOLOS - E-mail: antoniotguerra@gmail.com
} 


\section{INTRODUÇÃO}

Em virtude da modernização das sociedades, do aumento do consumo e da utilização indiscriminada dos recursos naturais, fez-se necessário a criação de Áreas Protegidas e de Unidades de Conservação. O Sistema Nacional de Unidades de Conservação (SNUC, 2000) afirma que uma Unidade de Conservação (UC) é um espaço territorial instituído pelo poder público com a finalidade específica de conservar as características naturais relevantes presentes na área, podendo ser de Proteção Integral ou de Uso Sustentável.

O Parque Nacional de Yellowstone foi criado nos Estados Unidos da América em 1872 e é considerado o primeiro parque do mundo. No Brasil, a criação da primeira UC ocorreu em 1937, com a implementação do Parque Nacional do Itatiaia.

O SNUC divide as Áreas Protegidas em dois grupos: as de Proteção Integral, que possuem como objetivo principal a conservação da biodiversidade, sendo de uso restrito; e Áreas de Uso Sustentável, que permitem a utilização dos recursos naturais de forma controlada (SNUC, 2000).

Dentro do grupo de Unidades de Conservação de Proteção Integral, destacam-se os Parques Nacionais, onde é previsto o uso para desenvolvimento de pesquisa científica e turismo ecológico. Porém, esta atividade deve ser realizada de forma controlada, visando a conservação do ambiente natural e a conscientização dos visitantes.

Assim, os Parques Nacionais Brasileiros estão sujeitos às diretrizes estabelecidas pelo Decreto $\mathrm{n}^{\circ} 84.017$ de 21/09/1979, que contém as recomendações e orientações para a elaboração do Plano de Manejo. A meta principal é preservar amostras de ecossistemas naturais e direcionar as ações nessas UCs, para que cumpram com os objetivos para as quais foram criadas (ICMBIO, 2002).

O Parque Nacional da Serra da Bocaina (PNSB) é um exemplo de UC de Proteção Integral que além de receber turistas do mundo todo, devido à sua beleza natural, sofre com a pressão antrópica do entorno. Diante disso, os gestores do Parque definiram três áreas prioritárias de monitoramento dos impactos, principalmente por conta dos acessos ao parque: a RJ 165 (rodovia Paraty-Cunha), a Travessia Mambucaba (antigo caminho do ouro) e a Vila de Trindade (ICMBIO, 2002).

O PNSB foi escolhido como área de estudo do presente trabalho, pois é uma das maiores áreas protegidas do Bioma Mata Atlântica, altamente degradado e fragmentado devido à expansão urbana. Assim, o aumento da atividade turística no PNSB pode provocar impactos ambientais, que segundo Guerra e Guerra (2013) caracteriza modificações causadas ao meio ambiente, influenciando na estabilidade do ecossistema.

Quando as UCs se encontram em áreas de difícil acesso, os principais caminhos utilizados são as trilhas. Andrade (1997 e 2005) destaca que as trilhas têm a função de prover o deslocamento e que, muitas vezes, são os únicos meios de acesso às UCs, oferecendo oportunidades do contato com a natureza. Portanto, as trilhas têm a função de levar os visitantes até os pontos atrativos da área. 
Assim, o uso das trilhas pode impactar o ecossistema como um todo, provocando a fuga de animais, erosão, compactação e perda de matéria orgânica do solo devido ao pisoteio e redução das espécies vegetal no entorno (FONTOURA; SIMIQUELI, 2007).

Diante disso, pensando na conservação de Áreas Protegidas, o presente trabalho tem como objetivo analisarmos impactos do uso da trilha para a Piscina do Caixa D'Aço, localizada na Vila de Trindade, dentro do Parque Nacional da Serra da Bocaina.

\section{MATERIAIS E MÉTODOS}

\section{Área de Estudo}

O Parque Nacional da Serra da Bocaina (PNSB) foi criado através do decreto Federal $\mathrm{n}^{\circ}$ 68.172, de 04 de fevereiro de 1971, com área de 134.000 ha, sendo posteriormente modificado pelo Decreto Federal $\mathrm{n}^{\circ} 70.694$, de 08 de junho de 1972, passando a ter área de 104.000 ha. Do total, cerca de 60\% localiza-se no Estado do Rio de Janeiro (municípios de Angra dos Reis e Paraty) e 40\% no Estado de São Paulo (municípios São José do Barreiro, Ubatuba e Cunha), segundo dados do ICMBIO (2012). A trilha da Piscina do Caixa D'Aço está localizada próxima a vila de Trindade, marcando a divisa entres os estados do Rio de Janeiro e São Paulo, permitindo o acesso à Piscina Natural e possui, aproximadamente, 450 metros de extensão (Figura 1).

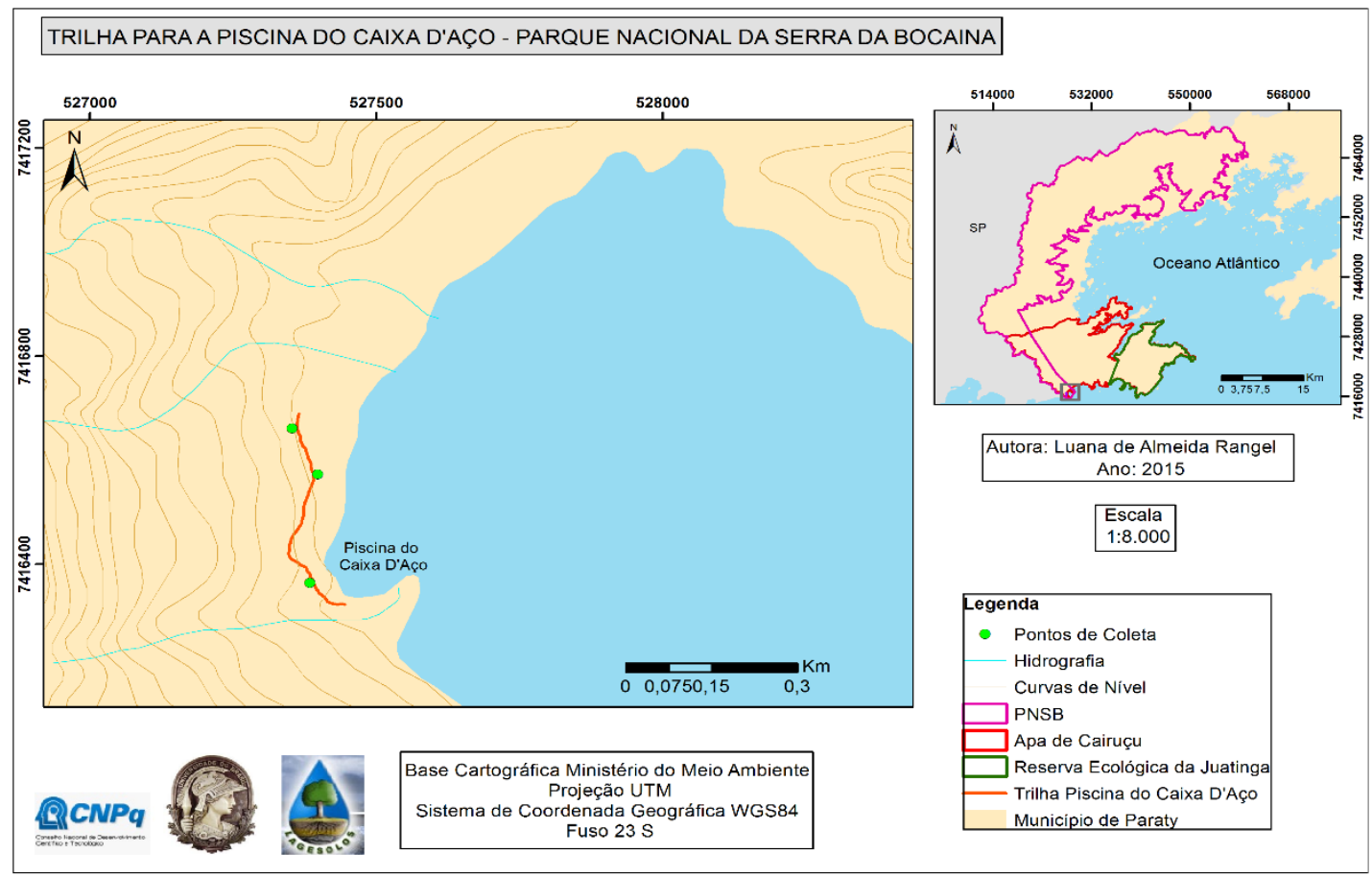

Figura 1. Mapa de localização do Parque Nacional da Serra da Bocaina e dos pontos de coleta na Trilha da Piscina do Caixa D'Aço. Elaboração: L. A. Rangel, 2015.

O clima da região do PNSB é influenciado pela compartimentação regional do relevo e pelo desnivelamento altimétrico, que produzem descontinuidades no padrão de distribuição pluviométrica e de temperatura. Este fator reflete o efeito orográfico da Serra do Mar que atua 
sobre o comportamento dos sistemas frontais, principais responsáveis pela pluviosidade regional. Logo, a classificação climática regional é tropical úmido (COELHO NETO; DANTAS, 1995).

Com relação às características geológicas e geomorfológicas o PNSB situa-se no Planalto da Bocaina (PONÇANO et al., 1981; ALMEIDA, 1974). A área onde está localizada a trilha corresponde ao relevo de Montanhas e Morros, que são relevos sustentados por xistos, gnaisses, granitos e charnoquitos, que dão origem a solos de alteração, residuais e superficiais delgados e com frequentes afloramentos de rocha devido às declividades acentuadas. Já os solos superficiais da região, possuem textura argilosa ou argilo siltosa correspondendo a associações de Cambissolos Háplicos Distróficos, ocorrendo também Latossolos VermelhosAmarelos com horizonte A moderado e proeminente nos topos e encostas mais suaves (ICMBIO, 2002).

A área de estudo situa-se dentro dos domínios florísticos da Zona Neotropical e agrupa a diversidade deformas vegetacionais em três tipos de formações: a Floresta Ombrófila Densa (Submontana, Montana e Alto Montana), expressão dominante na região, Floresta Ombrófila Mista Alto Montana e os campos de altitude (IBGE, 1992). Segundo o ICMBio (2002), na área de Trindade há predomínio de Floresta Ombrófila Densa secundária, em estádio médio e avançado de recuperação.

\section{Coletas e Análises Laboratoriais}

Para a realização da pesquisa, foram coletadas amostras de solo em três pontos da trilha Praia do Cachadaço-Piscina Natural do Cachadaço, na profundidade de 0-10 cm no mês de abril de 2015. Para cada ponto coletado foram realizadas três repetições e os resultados apresentados correspondem às médias dessas repetições. Além disso, foram mapeados impactos e degradações presentes na trilha, como processos erosivos, presença de lixo e falta de estruturas de manejo.

A análise da textura do solo foi realizada a partir do método de dispersão das partículas (EMBRAPA, 2011), onde são pesadas 20 gramas de amostras e adicionados $10 \mathrm{ml}$ de dispersante e $100 \mathrm{ml}$ de água destilada. Posteriormente, a amostra é levada ao agitador por 15 minutos e lavada na peneira de $0,053 \mathrm{~mm}$, onde a areia é retida e a fração silte+argila vai para uma proveta de $1000 \mathrm{ml}$. Transcorrido o tempo de acordo com a temperatura, é introduzida uma pipeta de $50 \mathrm{ml}$, onde é coletada a fração argila. As frações são levadas a estufa por 24 horas a $105{ }^{\circ} \mathrm{C}$. Por fim, a amostra de areia é passada na peneira de $0,2 \mathrm{~mm}$ para separar areia fina da areia grossa. Depois de pesadas as frações, compara-se os resultados com o triângulo textural (LEMOS; SANTOS, 1996).

Já para a determinação da densidade do solo foi utilizado o método do anel volumétrico, proposto pela Embrapa (2011), onde foram coletadas amostras em anel de aço de volume conhecido $\left(100 \mathrm{~cm}^{3}\right)$. Após esse procedimento, as amostras são retiradas do anel, pesadas, levadas a estufa e deixadas a $105^{\circ} \mathrm{C}$ por 24 horas. Depois do tempo decorrido, são 
pesadas e a densidade será determinada a partir da fórmula abaixo, onde $\mathrm{D}$ representa a densidade $\left(\mathrm{g} / \mathrm{cm}^{3}\right) ; \mathrm{a}=$ massa da amostra seca a $105^{\circ} \mathrm{C}(\mathrm{g}) ; \mathrm{e} \mathrm{b}=\operatorname{volume}$ do anel $\left(\mathrm{cm}^{3}\right): \mathrm{D}=\frac{\mathrm{a}}{\mathrm{b}}$.

Por fim, a porosidade do solo - que determina o volume de poros totais ocupado por água e/ou ar, estando diretamente relacionada com a densidade e a compactação do solo - foi calculada a partir da fórmula abaixo, onde $\mathrm{PT}=$ porosidade total; $\mathrm{a}=$ densidade de partículas $\left(\mathrm{g} / \mathrm{cm}^{3}\right)$ e $\mathrm{b}=$ densidade do solo $\left(\mathrm{g} / \mathrm{cm}^{3}\right): P T=\left(\frac{a-b}{a}\right) \times 100$.

\section{RESULTADOS}

A Piscina Natural do Caixa D'Aço é um geossítio que possui grande fluxo de visitantes ao longo do ano. Segundo o ICMBio (2014) por apresentar variada fauna marinha é extremamente sensível a impactos ambientais. $\mathrm{O}$ acesso à Piscina só é possível através da utilização de barcos que saem da praia do Meio ou pela trilha.

A trilha para a Piscina Natural se inicia no final da praia do Caixa D'Aço, próximo a diversos blocos rochosos. Apesar de apresentar apenas 450 metros de extensão, possui trechos declivosos e de difícil acesso aos usuários. É possível observar no perfil de elevação (Figura 2) que o ponto de altitude máxima da trilha é de 50 metros e que a mesma se encontra em ambiente de Floresta Ombrófila Densa Secundária.

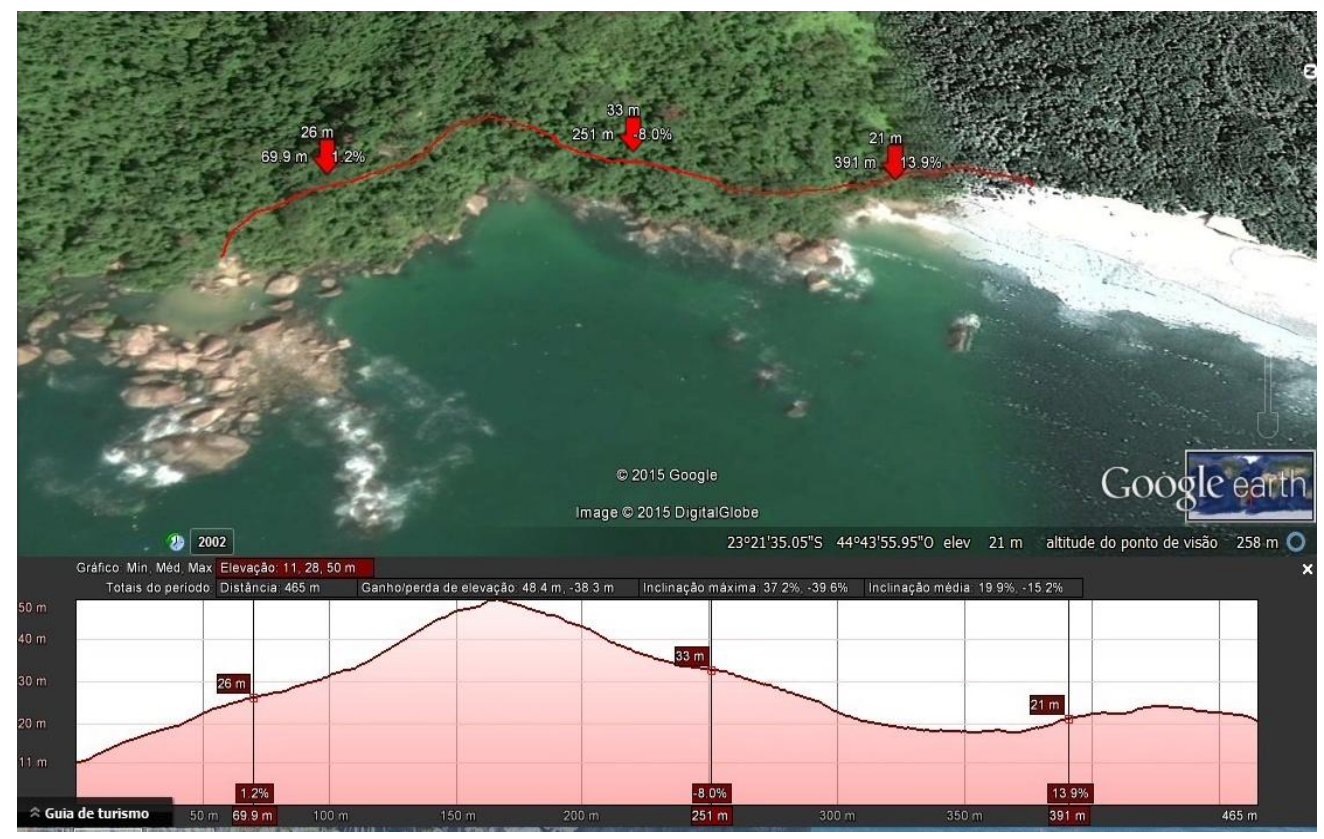

Figura 2. Perfil de Elevação e localização dos pontos de coleta na trilha para a Piscina Natural do Caixa D’Aço. Fonte: Google Earth.

A trilha apresenta raízes, blocos rochosos expostos, pontos de acumulação de água, ravinas e perda de borda crítica ao longo de todo o seu traçado. Além disso, o solo está bastante compactado, devido ao intenso pisoteio e a presença de lixo deixado pelos usuários, ocorrendo ao longo de toda a trilha. Como a trilha foi feita sem planejamento, o leito é muito estreito na maior parte do traçado $(0,60 \mathrm{~cm}$ de largura), podendo chegar, em alguns pontos, a 1,5 metros de largura. Além disso, alguns atalhos já foram criados, pois dois pontos da trilha 
erodiram e foi necessário refazer o caminho. Verificam-se ainda, diversas estruturas de manejo, porém elas estão degradadas ou são insuficientes (Figura 3).
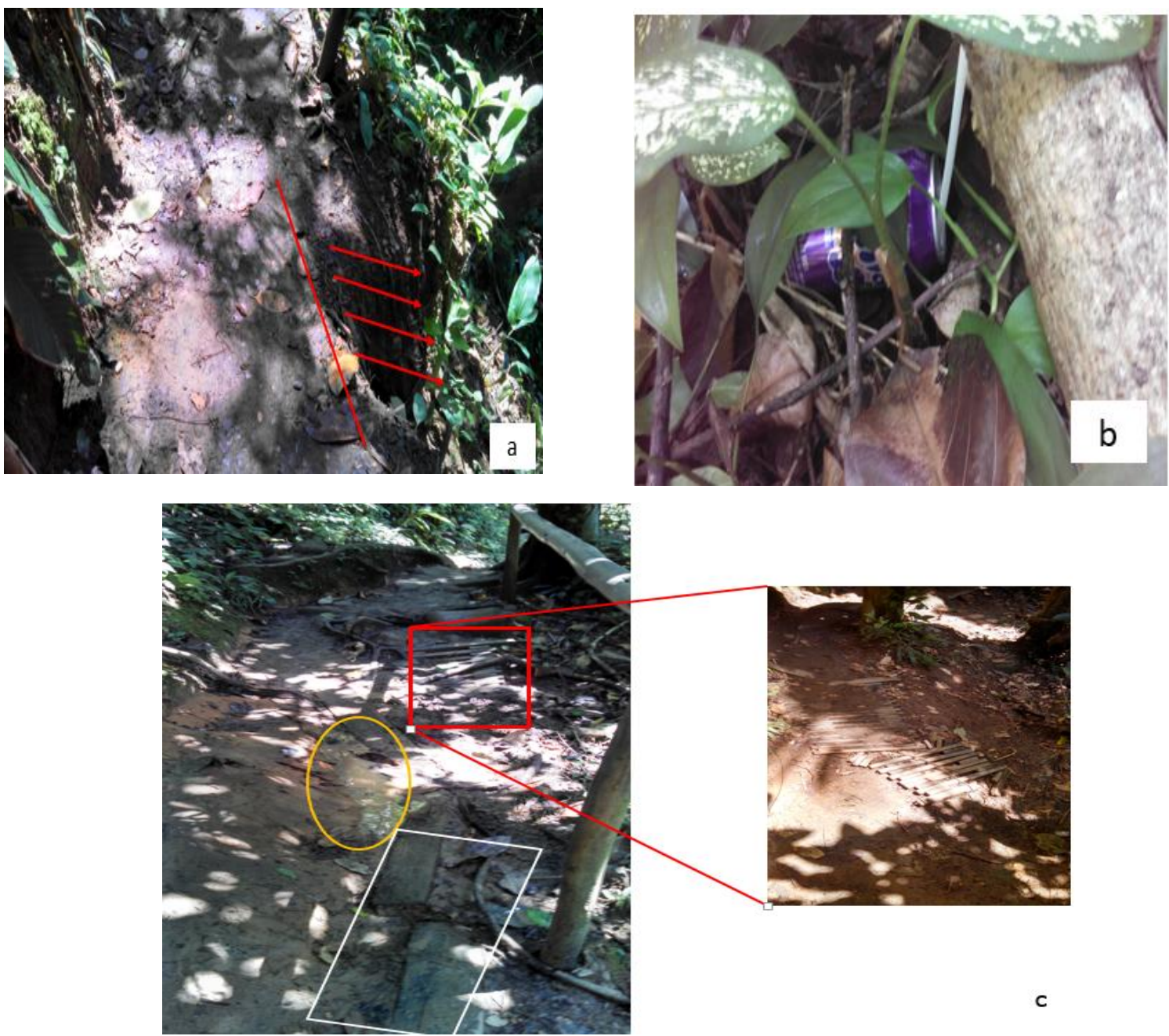

Figura 3. Principais impactos e degradações observadas na trilha Praia do Caixa D'Aço Piscina Natural do Caixa D'Aço. (a) Erosão com perda de borda crítica do leito da trilha; (b) presença de lixo; (c) acumulação de água no leito da trilha (destaque em amarelo), estrutura de manejo que foi erodida (destaque em vermelho e no detalhe) e tábuas de madeira improvisadas (destaque em branco).

Kroeff (2010) destaca que é comum, nas áreas de trilha, deparar-se com ambientes degradados, com a presença de lixo, pichação, queimadas, entre outros, em um ambiente natural que objetiva a conservação, aparenta ser uma afronta aos olhos dos visitantes e administradores de áreas protegidas. É importante destacar que os visitantes, muitas vezes, são responsáveis por essa degradação, já que eles mesmos jogam lixo e picham, além de outras ações impactantes.

O primeiro ponto de coleta está localizado em uma área com diversos blocos rochosos e raízes aparentes, apesar de ter um corrimão os usuários possuem grande dificuldade, pois precisam passar em cima de um bloco rochoso e correm o risco de cair da encosta (Figura 4). 


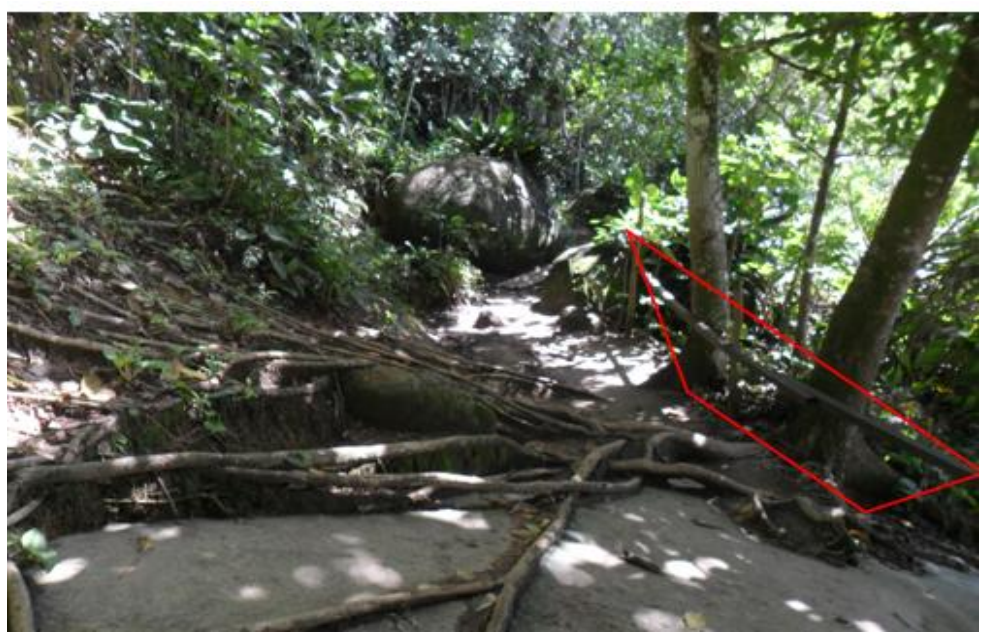

Figura 4. Visão geral do primeiro ponto de coleta, com a presença de raízes e blocos rochosos no leito da trilha. Destacado em vermelho a estrutura de manejo insuficiente.

Acervo: L. A. Rangel, 2015.

Já o segundo ponto de coleta, está localizado próximo a degraus de madeira e a um caminho que foi fechado porque a passagem foi erodida. Neste ponto o leito da trilha possui aproximadamente 1,2 metros de largura, há presença de raízes e serapilheira e o solo encontra-se muito compactado (Figura 5).

Cole (1993) destaca que o pisoteamento frequente provoca a perda do material orgânico dos primeiros centímetros do solo, causando assim a compactação do mesmo. $\mathrm{O}$ pisoteio causa o corte, a quebra e a exposição de raízes da vegetação, sendo assim as plantas que estão nas trilhas tendem a reduzir de tamanho podendo gerar a morte da planta e alargamento do leito da trilha.

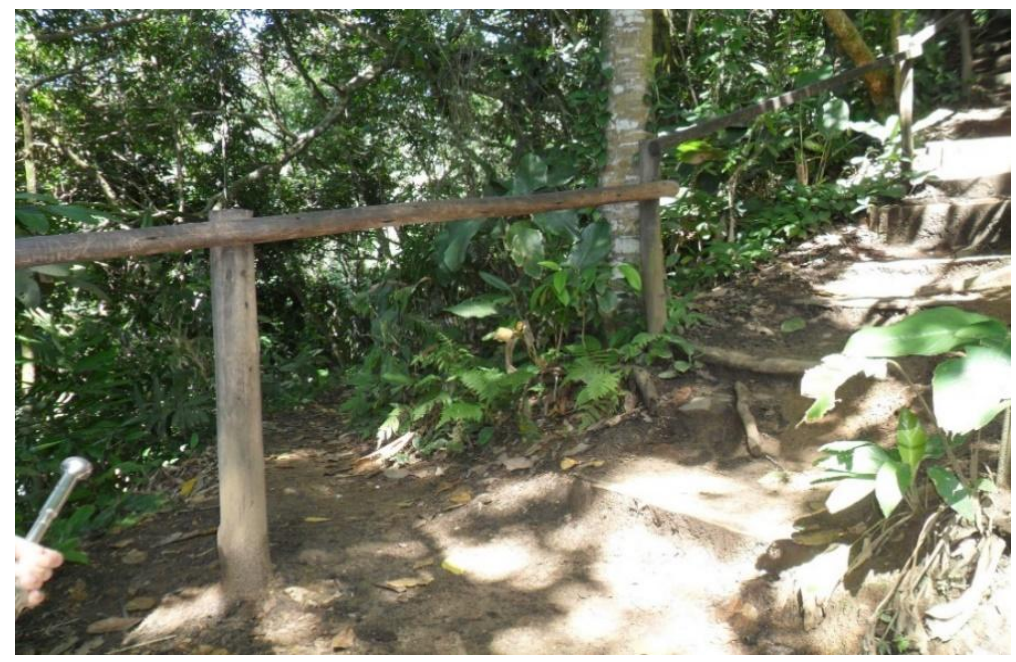

Figura 5. Atalho fechado e degraus erodidos no segundo ponto de coleta. Acervo: L. A. Rangel, 2015.

Por fim, no terceiro ponto de coleta foi possível observar o início de um processo de ravinamento com acúmulo de serapilheira e, por estar localizado em uma área de declive, os 
sedimentos são carreados pela encosta quando ocorrem eventos chuvosos, danificando algumas estruturas de manejo e aumentando as possibilidades de erosão (Figura 6).

Rangel e Guerra (2014) ao analisarem trilhas na Reserva Ecológica da Juatinga, encontraram problemas semelhantes - presença de ravinas e processos erosivos iniciais, mesmo em áreas de Floresta Ombrófila.

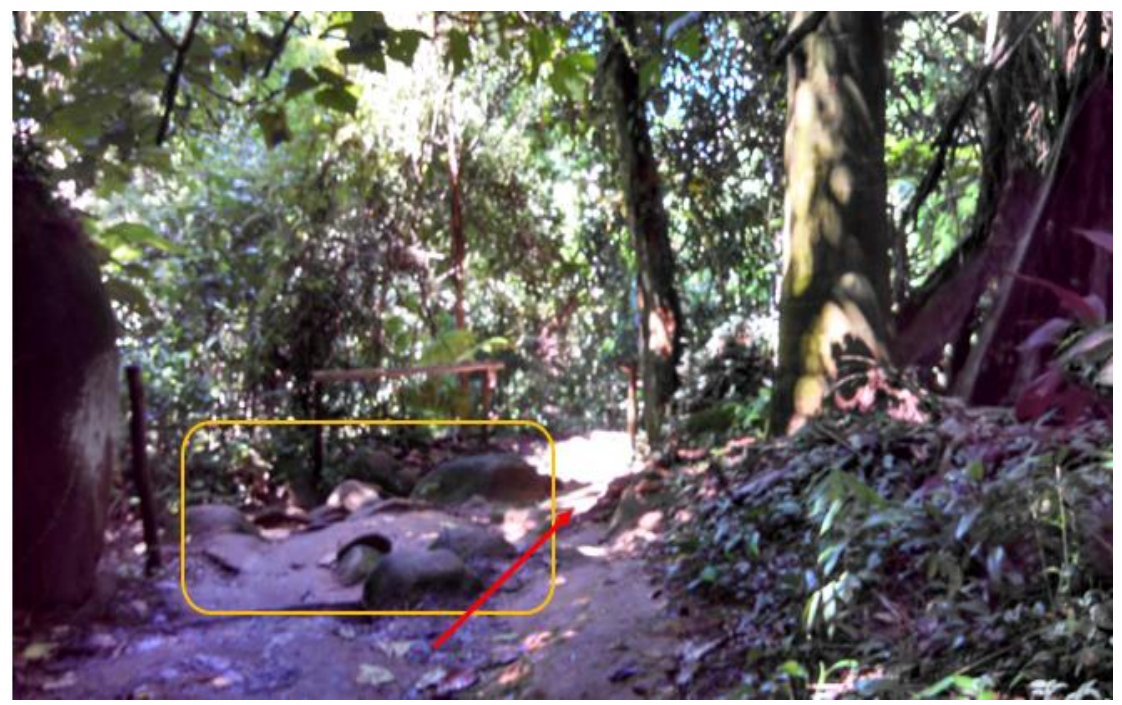

Figura 6. Vista geral do terceiro ponto de coleta com a presença de blocos rochosos (destaque em amarelo) e ravina com acumulação de serapilheira (destaque em vermelho). Acervo: L. A. Rangel, 2015.

Com relação à análise da textura do solo (Tabela 1), observa-se que o ponto 1 apresenta maior concentração de argila $(16,73 \%)$ e de silte $(34,02 \%)$, partículas mais finas do solo, que, sem o manejo adequado, são facilmente levadas pela água, aumentando o risco de processos erosivos. Já os outros dois pontos de coleta apresentaram menores teores de silte $(21,01 \%$ e $18,14 \%$, respectivamente).

Tabela 1. Textura do solo em porcentagem nos pontos de coleta na profundidade de $0-10 \mathrm{~cm}$.

\begin{tabular}{ccccccc}
\hline $\begin{array}{c}\text { Ponto } \\
\text { de } \\
\text { Coleta }\end{array}$ & Profundidade & $\begin{array}{c}\text { Areia } \\
\text { Fina } \\
(\boldsymbol{\%})\end{array}$ & $\begin{array}{c}\text { Areia } \\
\text { Grossa } \\
(\boldsymbol{\%})\end{array}$ & $\begin{array}{c}\text { Argila } \\
(\boldsymbol{\%})\end{array}$ & $\begin{array}{c}\text { Silte } \\
(\boldsymbol{\%})\end{array}$ & Textura \\
\hline Ponto 1 & $0-10 \mathrm{~cm}$ & 11,05 & 28,2 & 26,73 & 34,02 & Franco -Argilosa \\
Ponto 2 & $0-10 \mathrm{~cm}$ & 12,15 & 41,05 & 25,79 & 21,01 & Franco - Argilo - Arenosa \\
Ponto 3 & $0-10 \mathrm{~cm}$ & 10,45 & 46,65 & 24,76 & 18,14 & Franco -Argilo - Arenosa \\
\hline
\end{tabular}

Com relação aos resultados das análises de densidade e porosidade do solo apresentados na Figura 7, verifica-se que o segundo ponto de coleta está sofrendo maior impacto do pisoteio, pois está mais compactado (1,38 g/cm³). Segundo Kiehl (1979), valores 
de densidade aparente entre 1,1 e 1,6 $\mathrm{g} / \mathrm{cm}^{3}$ representam predominância de frações minerais, enquanto que em florestas a densidade aparente pode variar entre $0,6 \mathrm{e} 0,8 \mathrm{~g} / \mathrm{cm}^{3}$.

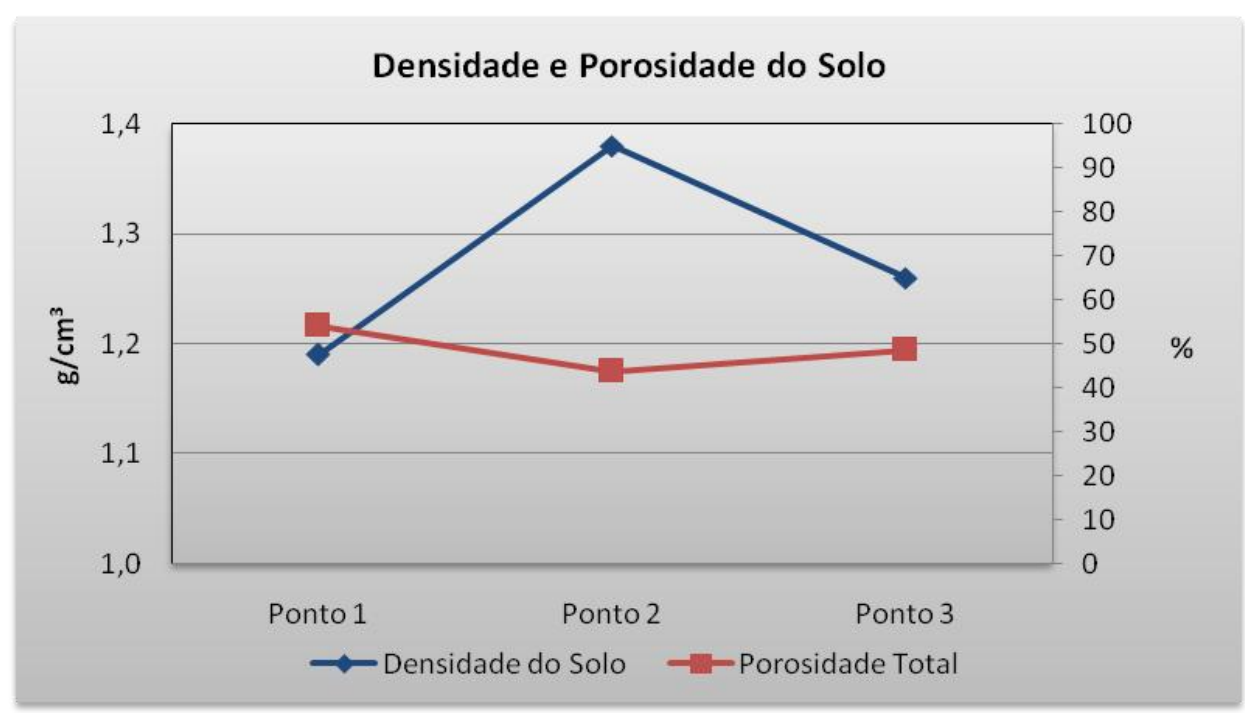

Figura 7. Densidade e Porosidade do solo nos três pontos de coleta na profundidade de 0-10 $\mathrm{cm}$. A porosidade está representada em porcentagem e a densidade do solo em $\mathrm{g} / \mathrm{cm}^{3}$.

Já o ponto 1 apresentou o menor valor de densidade $\left(1,19 \mathrm{~g} / \mathrm{cm}^{3}\right)$ e, consequentemente o maior valor de porosidade $(54,05 \%)$ evidenciando melhor estruturação do solo, maior possibilidade de infiltração da água da chuva, menores taxas de escoamento superficial e redução de processos erosivos.

De acordo com Takahashi (1998), o pisoteio das trilhas compacta os solos alterando sua porosidade em razão da redução do volume de macroporos. Este aumento na compactação eleva a resistência mecânica do solo à penetração de raízes e à infiltração de água, reduzindo inclusive a regeneração natural. Nas trilhas o pisoteio é inevitável, porém, quando não há estrutura de manejo adequada e o pisoteio é constante pode aprofundar pontos de alagamento na trilha.

Já os percentuais de porosidade encontrados, podem ser considerados de baixa a média suscetibilidade à erosão (entre 35 e $55 \%$ ) segundo o que foi proposto por Lima (2008) no estudo feito na bacia hidrográfica do rio Macaé, e por Rangel (2014) no estudo de trilhas na Área de Proteção Ambiental do Cairuçu. Os resultados obtidos estão em acordo com os dados apresentados por Maganhotto et al. (2010) e Oliveira et al. (2013), que também encontraram valores médios de porosidade no leito das trilhas.

Nas áreas onde as feições erosivas estão desenvolvidas (Figuras 3 e 6) é necessário utilizar técnicas de bioengenharia, como a aplicação de geotêxteis. Eles são malhas de fibras ou de materiais sintéticos biodegradáveis, que controlam a erosão e auxiliam na recuperação de áreas degradadas. Funcionam como proteção imediata e temporária ao solo contra os agentes erosivos, como as gotas de chuva e o escoamento superficial, enquanto a vegetação não se estabelece na encosta. Após o estabelecimento da vegetação, as raízes das plantas e as 
fibras do geotêxtil agirão juntas e aumentarão a coesão das partículas do solo (GUERRA et al., 2010; GUERRA et al. 2015).

Além disso, a utilização de canaletas de drenagem em áreas de convergência de fluxos para evitar concentração do fluxo; o ordenamento do sistema de drenagem; a utilização de barreiras que retenham os sedimentos e a recolocação de algumas estruturas de manejo como, por exemplo, as da Figura 3c, podem auxiliar na conservação das trilhas.

\section{CONCLUSÕES}

As trilhas são, muitas vezes, o único caminho para se chegar a determinado lugar, principalmente em UCs, onde o apelo ao ambiente natural possui grande importância. Porém, sua elevada utilização pode gerar diversos impactos, desde a presença de lixo até processos erosivos mais significativos, como a presença de ravinas e erosões do leito da trilha.

Considerando que o manejo adequado é fundamental para a qualidade do solo, percebe-se que as trilhas, que possuem função não só turística, mas também social, precisam ser melhor conservadas. Isto deve ocorrer, principalmente quando as mesmas estão inseridas em um Parque Nacional, já que o objetivo desta é a conservação de recursos naturais e do espaço e as trilhas, quando degradadas vão contra esse preceito de conservação.

É necessário recuperar as áreas já degradadas, através da utilização de técnicas de bioengenharia, como geotêxteis e instalar estruturas de manejo mais eficientes, como diques e barreiras de água que evitam a circulação de água no leito da trilha e o aprofundamento de processos erosivos. Além disso, é fundamental conscientizar os turistas e demais usuários, no sentido de promover a adoção de condutas adequadas e menos impactantes, pois, como foi constatado, os próprios usuários deixam lixo e impactam as trilhas.

Os resultados apontam para a importância dos estudos de campo, do planejamento e da recuperação das trilhas. O desenvolvimento dessas atividades auxilia na elaboração de diagnósticos de degradação das trilhas que venham a compor a proposição de medidas reparadoras, visando à diminuição do impacto na UC.

\section{AGRADECIMENTOS}

À Fundação Carlos Chagas Filho de Amparo à Pesquisa do Estado do Rio de Janeiro (FAPERJ) e ao Conselho Nacional de Desenvolvimento Científico e Tecnológico (CNPq) pelo financiamento da pesquisa.

\section{REFERÊNCIAS BIBLIOGRÁFICAS}

ALMEIDA, F. F. M. Os fundamentos geológicos do relevo paulista. Boletim do Instituto de Geologia, São Paulo, v.41, p.169- 263, 1964.

ANDRADE, J. V. Turismo: Fundamentos e dimensões. São Paulo: Ed. Ática, 1997.

ANDRADE, W. J. Manejo de trilhas para o ecoturismo. In: NEIMAN, Z. \&MENDONÇA, R. Ecoturismo no Brasil. São Paulo: Manole, 2005. 
COELHO NETO, A. L.; DANTAS, M. E. Recursos hídricos. In: MITCHELL, G. (Org.), Relatório final do projeto Mata Atlântica, UFRJ/FURNAS. Centrais Elétricas S.A./Fundação BIO-RIO, cap. IV, p. 110-149, 1995.

COLE. Minimizing Conflict between Recreation and Nature Conservation. In: SMITH, D.S. e HELLMUND, P.C. (org). Ecology of Greenways: Design and Function of Linear Conservation Areas. Univ. of Minnesota Press, Minneapolis, MN, 1993. p. 105 -122.

EMBRAPA. Manual de métodos de análise de solos. DONAGEMMA, G. K.; CAMPOS, D. V. B.; CALDERANO, S. B.; TEIXEIRA; W. G.; VIANA, J. H. M. (Org.). Rio de Janeiro: Embrapa Solos, 2011. 230 p.

GUERRA, A. J. T.; BEZERRA, J. F. R.; LIMA, L. D. M.; MENDONÇA, J. K. S.; GUERRA, T. T.; BUHMANN, C.; PATERSON, D. G.; PIENAAR, G.; NELL, J. P.; MULIBANA, N. E.; DEVENTER, P. W. V.; FULLEN, M. A. Land rehabilitation with the use of biological geotextiles, in two different countries. Sociedade \& Natureza, Uberlândia: EDUFU, v. 22, n 3, p. 431-446, 2010.

GUERRA, A. T.; GUERRA, A. J. T. Novo dicionário geológico-geomorfológico. 9. ed. Rio de Janeiro: Bertrand Brasil, 2013.

GUERRA, A. J. T., BEZERRA, J. F. R., FULlEN, M. A., J. K. S. MENDONÇA, J. K. S., JORGE, M. C. O. The effects of biological geotextiles on gully stabilization in São Luís, Brazil. Natural Hazards, v. 75, p. 2625-2636, 2015.

ICMBIO. Plano de Manejo do Parque Nacional da Serra da Bocaina. 2002. Disponível em: $\quad$ http://www.icmbio.gov.br/parnaserradabocaina/extras/62-plano-de-manejo-emonitorias.html. Acesso: 10 mar. 2015.

KIEHL, E. J. Manual de edafologia, relações solo-planta. São Paulo: Ceres, 1979.

KROEFF, L. L. Contribuição metodológica ao planejamento de trilhas ecoturísticas no Parque Nacional da Serra dos Órgãos (PARNASO), RJ. 2010. 199f. Dissertação (Mestrado em Geografia) - Instituto de Geociências, Universidade Federal do Rio de Janeiro, Rio de Janeiro, 2010.

LEMOS, R. C.; SANTOS, R. D. dos. Manual de descrição e coleta de solo no campo. Sociedade Brasileira de Ciência do Solo - Centro Nacional de Pesquisa de Solos: Campinas, 1996.

LIMA, L. D. da M. Suscetibilidade à Erosão dos Solos nas Sub -bacias do médio e alto cursos da Bacia do Rio Macaé / RJ. 127 f. Dissertação (Mestrado em Geografia) - Instituto de Geociências - Universidade Federal do Rio de Janeiro, Instituto de Geociências, Rio de Janeiro, 2008.

MAGANHOTTO, R. F.; SANTOS, L. J. C.; SOUZA, L. C. P.; MIARA, M. A. Variação dos atributos físicos do solo devido ao trânsito de pessoas em trilha localizada na Região de Paranaguá - Pr. Revista Geografar, Curitiba, v. 5, n. 2, p. 94-114, jul./dez. 2010.

MMA (Ministério do Meio Ambiente). Sistema Nacional de Unidades de Conservação (SNUC). 2000. MMA, SNUC, Brasília.

OLIVEIRA, J. G. R.; FILHO TAVARES, J.; BARBOSA, G. M. C. Qualidade física do solo das trilhas do parque estadual do Cerrado - PR. Ciências Agrárias, Londrina, v. 34, n. 4, p. 1715-1722, 2013. 
PONÇANO, W. L. et. al. Mapa geomorfológico do Estado de São Paulo; escala 1:1.000.000. São Paulo. Instituto de Pesquisas Tecnológicas do Estado de São Paulo, 1981.

RANGEL, L. A. O Impacto da Utilização de Trilhas na Área de Proteção Ambiental de Cairuçu - Paraty - Rio de Janeiro. Dissertação (Mestrado em Geografia) - Universidade Federal do Rio de Janeiro, Instituto de Geociências, Rio de Janeiro: PPGG UFRJ, 2014 186f.

RANGEL, L. A.; GUERRA, A. J. T. Degradação de trilhas na Reserva Ecológica da Juatinga em Paraty - Rio de Janeiro. Revista Ambiente \& Água, v.9, p.752 - 766, 2014.

SCHENINI, P. C.; COSTA, A. M.; CASARIN, V. W. Unidades de Conservação: aspectos históricos e sua evolução. In: CONGRESSO BRASILEIRO DE CADASTRO TÉCNICO MULTIFINALITÁRIO. Florianópolis: UFSC, 2004. 7p.

SIMIQUELI, R. F.; FONTOURA, L. M. Manejo de trilhas: estratégias para a conservação ecológica em áreas naturais protegidas. Anais do VIII Congresso de Ecologia do Brasil, 23 a 28 de Setembro de 2007, Caxambu - MG. CD-ROM.

TAKAHASHI, L. Y. Caracterização dos visitantes, suas preferências e percepções e avaliação dos impactos da visitação pública em duas unidades de conservação do Estado do Paraná. 1998. 129f. Tese (Doutorado em Engenharia Florestal) - Universidade Federal do Paraná, Curitiba. 